\title{
Editorial
}

\section{The weight of our nation}

\author{
Hans Krueger, PhD $(1,2)$
}

Canadians spent an estimated $\$ 228$ billion on health care in 2016. That represents $11.1 \%$ of our total economy, or $\$ 6,299$ per person. Almost $40 \%$ of all public expenditures are allocated to fund health care. ${ }^{1}$ Put succinctly, that is a lot of money! This issue of Health Promotion and Chronic Disease Prevention in Canada places a spotlight on three diseases that contribute to this economic burden of health care in Canada.

Pelletier and coauthors ${ }^{2}$ estimate that 700000 Canadians report symptoms consistent with generalized anxiety disorder (GAD) and that $30 \%$ of these individuals' needs for health care are not being met. Amankwah and colleagues ${ }^{3}$ estimate that 99000 Canadians were living with multiple sclerosis (MS) in 2011 and that this number will increase to 134000 by 2031 . Estimated health care and out-of-pocket costs attributable to MS in 2011 were $\$ 1.48$ billion.

Bilandzic and Rosella ${ }^{4}$ calculate that 2156000 new cases of diabetes will be diagnosed in Canada during the 10-year period between 2011/12 and 2021/22, with attributable health care costs of $\$ 15.36$ billion, or $\$ 7,124$ per individual with diabetes. They further calculate that 283000 cases of diabetes and $\$ 2.03$ billion in costs could be avoided if the average body weight of Canadians were reduced by $5 \%$.

The focus on the relationship between diabetes and excess weight by Bilandzic and Rosella is appropriate as we estimate that $62 \%$ of type 2 diabetes in Canada is attributable to excess weight. ${ }^{5} \mathrm{~A}$ further $18 \%$ and $8 \%$, however, is attributable to physical inactivity and tobacco smoking, respectively. Based on Canadian Community
Health Survey (CCHS) data, the prevalence of tobacco smoking was reduced from $24.8 \%$ to $16.2 \%$ between 2001 and 2014 among Canadians aged 20 to 64 years. Similarly, the prevalence of physical inactivity has been reduced from $55 \%$ to $47 \%$. The biggest challenge, however, remains with excess weight. During that same time period, the prevalence of obesity increased from $15.3 \%$ to $20.6 \%$ (or a total of 4557000 Canadians). Most importantly, the prevalence of individuals with the highest levels of obesity has more than doubled. Both the health and economic burdens associated with obesity increase dramatically as weight increases.

The diverging trends in the prevalence of tobacco smoking and excess weight in Canada means that the economic burden attributable to excess weight is now $25 \%$ higher than that attributable to tobacco smoking. ${ }^{5}$ This crossover occurred in 2009 , and the gap between the economic burden attributable to excess weight and tobacco smoking has continued to widen.

Success in reducing the prevalence of tobacco smoking resulted in a $34 \%$ decrease in the attributable economic burden in Canada between 2000 and 2015, while the economic burden attributable to excess weight increased by $24 \%$. Within this context, how might we be able to achieve even the modest $5 \%$ reduction in weight suggested by Bilandzic and Rosella? Can we apply any of the lessons learned from the success addressing tobacco smoking to excess weight? During the last 60 years, we have learned that progress in the prevention of tobacco smoking has taken a comprehensive, long-term approach involving price increases (usually through taxation), controlling the advertising of tobacco products, counter-advertising, enhanced clinical cessation strategies and clean air legislation (smoking bans). ${ }^{6}$

While progress in the prevention of tobacco smoking has been challenging, and there is still much work to be done, addressing excess weight is likely to be even more complex. At its simplest, excess weight involves an imbalance of energy intake and output, but there is a much more complicated web of causal factors influencing weight-related problems. ${ }^{7}$ Organizations such as the World Health Organization $^{8}$ and the Centers for Disease Control and Prevention in the US $^{9}$ have begun to suggest a series of strategies to address excess weight, including the need to measure and evaluate obesity prevention efforts. What we do know is that the ability to successfully address excess weight at the population level will require a comprehensive, multidimensional approach in numerous spheres for at least a generation, with positive lifestyle choices consistently being reinforced by a supportive environment. ${ }^{6}$

The health of our nation, and our economy, requires that such a comprehensive, long-term approach be implemented now. We can no longer afford to wait.

\section{References}

1. Canadian Institute for Health Information (CIHI). Spending [Internet]. Ottawa (ON): CIHI; 2016. Available from: https://www.cihi.ca/en/spending -and-health-workforce/spending

2. Pelletier L, O’Donnell S, McRae L, Grenier J. The burden of generalized anxiety disorder in Canada. Health Promot Chronic Dis Prev Can. 2017; 37(2):54-62. 
3. Amankwah N, Marrie R, Bancej C, et al. Multiple sclerosis in Canada in 2011 to 2031: results of a microsimulation modelling study of epidemiological and economic impacts. Health Promot Chronic Dis Prev Can. 2017; 37(2):37-48.

4. Bilandzic A, Rosella L. The cost of diabetes in Canada over 10 years: applying attributable health care costs to a diabetes incidence prediction model. Health Promot Chronic Dis Prev Can. 2017;37(2):49-53.

5. Krueger H, Krueger J, Koot J. Variation across Canada in the economic burden attributable to excess weight, tobacco smoking and physical inactivity. Can J Public Health. 2015; 106(4):e71-e77.

6. Krueger H, Williams, D, Kaminsky B, McLean D. The health impact of smoking and obesity and what to do about it. Toronto (ON): University of Toronto Press; 2007.

7. Kumanyika S, Jeffery R, Morabia A, Ritenbaugh C, Antipatis V. Obesity prevention: the case for action. Int $\mathrm{J}$ Obesity. 2002;26:425-36.

8. World Health Organization (WHO). Population-based approaches to childhood obesity prevention [Internet]. Geneva (CH): WHO; 2012 [cited December 30, 2016]. Available from: http://www.who.int/dietphysicalactivity / c h i l d h o o d / W H O n e w _childhoodobesity_PREVENTION _27nov_HR_PRINT_OK.pdf

9. Centers for Disease Control and Prevention (CDC). Overweight \& obesity: prevention strategies \& guidelines [Internet]. Atlanta (GA): CDC [updated 2015 May 19; cited December 30, 2016]. Available from https://www .cdc.gov/obesity/resources/strategies -guidelines.html 